\title{
Apuntes sobre nihilismo: de la Ilustración a la bomba atómica. Un estudio comparativo entre J. G. Hamann y Günther Anders
}

\section{Notes on Nihilism: From Illustration to the Atomic Bomb. A Comparative Study Between J. G. Hamann and Günther Anders}

\author{
ABRAHAM HERNÁNDEZ PÉREZ, RAYCO HERRERA \\ UNIVERSIDAD DE LA LAGUNA
}

Recibido: 03/12/2019 Aceptado:24/02/2020

\begin{abstract}
RESUMEN
En este trabajo pretendemos comparar y poner en conexión la crítica de Hamann a la Ilustración y la crítica a la tecnología de Anders. La bomba atómica, entendida como paradigma tecnológico, se presenta como un punto de no retorno. Los orígenes de la lógica destructiva que la hace posible pueden ser rastreados hasta la Ilustración. En el periodo de las luces, Hamann aparece como un foco de resistencia frente a las sombras de un sistema que idealizó la racionalidad. A través de estos dos autores trazamos el recorrido del debate sobre el nihilismo desde su origen en la modernidad hasta el momento presente.
\end{abstract}

PALABRAS CLAVE

NIHILISMO, ILUSTRACIÓN, RACIONALIDAD, HAMANN, ANDERS

\section{ABSTRACT}

In this paper we intend to compare and connect Hamann's critique of the Enlightenment and Anders' critique of technology. The atomic bomb, understood as a technological paradigm, is presented as a point of no return. The origins of the destructive logic that makes it possible can be traced back to the Enlightenment. In the period of lights, Hamann appears as a focus of

(C) Contrastes. Revista Internacional de Filosofía, vol. XXV Nº1 (2020), pp. 61-76. ISSN: 1136-4076

Departamento de Filosofía, Universidad de Málaga, Facultad de Filosofía y Letras Campus de Teatinos, E-29071 Málaga (España) 
resistance against the shadows of a system that idealized rationality. Through these two authors we trace the path of the debate on nihilism from its origin in modernity to the present moment..

KEYWORDS

NIHILISM, ENLIGHTENMENT, RATIONALITY, HAMANN, ANDERS

El IMPLACABLE DESARROLlo DE LA TÉCNICA en el siglo pasado suscitó un intenso debate entre autores como Ernst Jünger y Martin Heidegger en torno al nihilismo. Estos retomaron en el texto Über die Linie el problema planteado por Nietzsche en el siglo XIX. Para este último el nihilismo era una fase que podía y debía ser superada bajo la afirmación del eterno retorno. Heidegger entendió que la posición nietzscheana se encontraba, todavía, dentro de la metafísica o del olvido del ser. Una crítica similar la sufrirá su colega Jünger, al que cataloga de «optimista» por afirmar que estamos sobre esa línea y proponer como superación la lucha contra la movilización total y la reivindicación de la retirada a los espacios de lo individual (el anarca). Para Heidegger esa línea no es rebasable porque, según él, el ser humano es la propia línea.

Probablemente todo lo bueno que haya acontecido durante el siglo XX, todos aquellos avances que han permitido tanto el desarrollo de las sociedades como el de los seres humanos, queden eclipsados por la aparición de la bomba atómica. Por vez primera la humanidad tiene a su alcance la posibilidad real de aniquilarse y poner fin a su historia. No obstante, la bomba fue velada como un «arma» más potente que las anteriores y, por ello, concebida como un medio. Aquella posibilidad no es más que otra creación bajo la lógica técnicocapitalista: la producción de la nada. Sin embargo, la bomba atómica no es un medio más, sino un fin. Lo que convierte al siglo XX en la consumación del nihilismo.

Si tuviéramos que dar una explicación rápida y simple de la llegada a este punto de no-retorno, lo más probable es que sintiéramos la tentación de practicar el deporte favorito de algunas corrientes de pensamiento, es decir, identificar como «vástago» de la irracionalidad cualquier elemento que produzca cierta disonancia. Sin embargo, el tema exige un tratamiento más serio y exhaustivo. Si de verdad deseamos encontrar respuestas más realistas es preciso alejarse de la dicotomía racional-irracional y del infructuoso debate que sigue suscitando. Precisamente, porque parece complicado imaginar un despliegue mayor de racionalidad que el que estaba en juego en el «Proyecto Manhattan». Esta tendencia a exonerar a la razón de responsabilidad ante ciertos horrores es la consecuencia lógica de la imposición de un paradigma cultural basado en la idealización del método racional. En pleno auge de 
dicho paradigma, es decir, cuando la Ilustración se encontraba en su momento más álgido, Hamann renegó del método científico por estar basado en las abstracciones, por aborrecer a las pasiones y por su pretensión de abarcarlo todo en un mismo sistema coherente. La Ilustración, según Hamann, tenía una idea mecanicista del mundo, concibiéndolo como algo estático, observable y manipulable, donde todo puede ser explicado a través de una misma estructura. Los modelos o teorías utilizados para explicar el mundo $-\mathrm{y}$ al propio individuo- daban por supuestas muchas cosas, pero también dejan fuera muchas otras, proyectando una imagen de un mundo ideal, plenamente cognoscible, sin misterios, y un sujeto racional exento de contradicciones o extrañezas. Esta negación de aspectos y valores cruciales de la vida convertían a la Ilustración, según Hamann, en el máximo exponente del nihilismo.

El propósito de este trabajo es destacar y comparar las figuras de J. G. Hamann y Günther Anders como críticos de lo que consideraron los rasgos nihilistas de su tiempo. Por un lado, Hamann como el precursor de dicha crítica, se opuso a los principios de la Ilustración por entender que ellos simplemente promovían la «absolutización de la razón» y acusó a los intelectuales de su época, especialmente a Kant, de nihilistas y de silenos invertidos. Por otro lado, Anders como el crítico que «desertó en la praxis» para evitar la consumación del nihilismo en la era atómica. Esta puesta en común nos permitirá mostrar que el fundamento de esta consumación se remonta a los orígenes de la razón abstracta de la modernidad. Para Anders su momento histórico se correspondía con el final de una época, pero también con la época del final. Los horrores que este nihilismo depararía apenas podían haber sido previstos por Hamann, pero tanto él como Anders se percataron de que el verdadero peligro está en lo que es velado. Ya sea un sistema filosófico vacío o una central nuclear.

\section{JoHANn Georg Hamann: EcCE hOMO}

Johann Georg Hamann nació en Königsberg en 1730. Vivió el auge y el frenesí de la Ilustración y aunque en un primer momento se sintiera emocionado con ésta, más tarde renegaría de los principios ilustrados. El punto decisivo en el devenir de su pensamiento, y por lo que es considerado un pensador original y valioso es, precisamente, ese cambio de perspectiva que se materializará en lo que se conoció como Metacrítica, es decir, una crítica que tiene como eje principal poner al descubierto las deficiencias y contradicciones, según él, inherentes al pensamiento ilustrado. Para entender bien esta cuestión es preciso retrotraernos un instante a la atmósfera del siglo XVIII. La Ilustración trató de combatir la ignorancia, la superstición e incluso la tiranía mediante el uso de la razón. Esta desplazó la figura de Dios para colocarse de manera orgullosa y triunfal en su lugar. El «siglo de las luces» tenía como finalidad arrojar luz a una sociedad envuelta en las sombras que había traído consigo la 
Edad Media. Para lograrlo había que someter todo a un férreo método que solo establecía como válido lo que resulta del uso estricto de la razón. Los modos de explicación al margen de este modelo serían considerados bárbaros. ${ }^{1}$ Dicho paradigma, cimentado en las exitosas aportaciones de Newton en la física, se quiso aplicar a todos los ámbitos de la vida. El presupuesto que hay de fondo es que la realidad es como un "puzle» donde todas las piezas tienen su lugar y el hombre mediante la razón debe ordenarlas y darles sentido dentro de una estructura o sistema.

El punto de inflexión de este segundo Hamann acontece en Londres, tras el varapalo que le supuso tratar de mitigar una enorme crisis existencial a través de aquellas ideas ilustradas. Desde ese momento comenzó a dudar de la operatividad real que dichas ideas podrían tener en relación con los aspectos que verdaderamente importaban a las personas. La manera de proceder de la razón, a través de generalizaciones, la abstracción y la conceptualización, impide todo discurso que trate de aportar algo sobre la singularidad. Aquella primera noche de crisis en Londres Hamann durmió al raso de la Ilustración; qué poco podían decir aquellas ideas sobre pesares y sentimientos concretos, qué pocas respuestas fueron capaces de dar sobre sus dudas, en definitiva, qué impotente se veían aquellas ideas a la hora de acallar un quejido que nacía desde lo más hondo del ser humano. Hamann se decepcionó tras sentir el fuerte contraste que existe entra la filosofía y la vida. Los modelos o teorías utilizados para explicar el mundo -y al propio individuo- proyectan una imagen de un mundo ideal, plenamente cognoscible, sin misterios, y un sujeto racional exento de contradicciones o extrañezas. ${ }^{2}$

Hamann desconfía de las potencias abstractivas de la razón, pues considera que establecen una fragmentación arbitraria del ser humano y la naturaleza, acuñando después un lenguaje académico para expresarla que acaban imponiéndose a la mentalidad popular, provocando el extrañamiento del ser humano concreto de la naturaleza, la historia, de sus semejantes y hasta de sí mismo, essto último especialmente en lo que a la corporeidad -y su lenguaje, sentimientos, acciones y pasiones- se refiere. ${ }^{3}$

La pretensión ilustrada de desentrañar la naturaleza a través de dicho método le parecía a Hamann excesivamente optimista e ingenua. Digamos

1 Tanto la obra Cassirer, Filosofía de la ilustración, como El espiritu de la Ilustración, de Todorov, son dos obras paradigmáticas que sintetizan de manera excelente el contexto histórico y los principios filosóficos predominantes durante la Ilustración.

2 Isaiah Berlin desarrolla más exhaustivamente la crítica de Hamann a la abstracción en su obra El mago del norte.

3 Canterla, C.: «La metacrítica de la razón ilustrada en Hamann», Daimon. Revista Internacional de Filosofia, suplemento 2 (2008), pp.337-345, p.339. 
que, «es esa incapacidad del racionalismo para percibir el todo, para captar las relaciones que tejen el mundo, la que induce a Hamann a defender una visión holista de la experiencia». ${ }^{4}$ De esta manera, Hamann se convierte en el primero en advertir en Alemania del contenido fraudulento de muchas de las obras de su época y, además, el primero en denunciarlo. Entendía que en ellas sólo había letra muerta en relación con nuestra supuesta naturaleza, la de los fenómenos o, incluso, la de Dios. En ese sentido, comenta Hamann en la Aesthetica in nuce, «Intentad leer la Ilíada, si antes habéis expurgado mediante la abstracción las dos vocales a y w, y decidme vuestra opinión acerca del entendimiento y las armonías del poeta». ${ }^{5}$ La naturaleza que aquellas obras y tratados describían nada tenía que ver con la auténtica, ya que ésta «obra a través de los sentidos y las pasiones. Quien mutila sus herramientas, ¿cómo puede percibir?, ¿se ven forzados a moverse incluso los miembros amputados?». ${ }^{6}$ Sin embargo, esto no quiere decir que en su crítica haya implícitamente un rechazo a la empresa científica, o como señala Cinta Canterla, haya una tendencia a retrotraer la Revolución científica o los avances liberales a modelos previos. Su crítica es el sello de la modernidad misma, con ella Hamann trata de denunciar la pretensión de reducir la realidad tan solo a lo que la ciencia estipula.

Hamann ve en el intelectualismo de su época una clara tendencia al artificio, lo tacha de meras creaciones culturales que suplantan a la realidad; de alguna manera niegan la vida e invierte sus valores. «Su objeción a la filosofía abstracta y erudita tendrá como objetivo denunciar su negación de los valores de la vida y la suplantación que hace de esta por un mundo intermedio de teoría que violenta a los seres humanos»». ${ }^{7}$ La opacidad de ciertos principios ilustrados convenció a Hamann de que tras ella empujaban fuerzas nihilistas. Dicho nihilismo es denunciado por Hamann a través del Sileno, una figura peculiar usada por Platón en El Banquete y luego en el Renacimiento, pero olvidada en los siglos posteriores a la Ilustración. Cinta Canterla caracteriza esta figura en su artículo «La cuestión del nihilismo en Hamann». Según la autora, dicha figura la retoma Hamann de Erasmo de Rotterdam y en su origen se articula a través de la voz de Alcibíades (Platón) para tratar de representar la contraposición entre la apariencia y la realidad. Alcibíades cuenta que Sócrates se parece a aquellos Silenos que estaban en los talleres de los artesanos y que abiertos en dos se podía ver cómo en su interior tenían estatuas de Dioses. El Sileno simplemente hace referencia a que la imagen exterior encubre una

4 Hamann, J.G.: Recuerdos socráticos y Aesthetica in nuce, Hermida Editores, Madrid, 2018, p. 17.

5 Ibid, p.103.

6 Ibid., p. 100

7 Canterla, C., «La cuestión del nihilismo en J.G. Hamann», Pensamiento, 70 (2014), núm. 264, pp. 577-600, p.596. 
belleza interior. De esta manera, para Hamann, el filósofo académico o de salón era un sileno invertido, es decir, tanto él como su filosofía parecían solemnes y brillantes, cargados de verdad, pero por dentro estaban vacíos, tanto la persona como aquellos sistemas metafísicos. La racionalidad abstracta, escindida de la vida y negadora de esta, configura, según Hamann, el verdadero Nihilismo. «De ahí viene la maldita contradicción en nuestros manuales de símbolos»dice Hamann- «que hasta día de hoy se encuadernan elegantemente con piel de oveja, pero por dentro -sí, por dentro, están llenos de huesos de muerto, llenos de vicio hipocrítico». 8

La pretensión utópica del proyecto ilustrado de alcanzar un conocimiento prístino, el rechazo de la parte corporal por identificarla con el error y los males revela, a ojos de Hamann, una patología de la razón. Dicha patología, denominada melancolía, es usada, según Cinta Canterla, como elemento de la crítica filosófica. Aparte de las consecuencias en el plano gnoseológico, este pensar a sangre fría, como lo denominaba Hamann, tiene consecuencias notables en el plano de la moral. Todo ese rechazo y condena de sentimientos o pasiones acaba insensibilizando por completo. Como explica Cinta Canterla, la melancolía de la razón es para Hamann «la causa del abuso y la explotación social y política, ${ }^{9}$ incapaces los poderosos de empatizar con las miserias de la deshumanización que ellos mismo provocan en sus semejantes». ${ }^{10}$ La metacrítica de Hamann trataba de promover un verdadero movimiento emancipatorio que ni negase aspectos de la vida ni absolutizase a la razón como la única guía válida del ser humano y, en ese sentido, «habría sido la primera argumentación de profundidad contra el nihilismo inherente a la razón abstracta de la modernidad». ${ }^{11}$ La nueva filosofía debería liberar al individuo de la alienación y la decadencia impuesta por esta filosofía basada en un concepto de razón completamente plano. En contraposición a los insatisfactorios planteamientos ilustrados Hamann comenta en Recuerdos socráticos: «Pero quizá toda la historia sea más mitología de lo que cree este filósofo» - refiriéndose a Bolingbroke - «y que, como la naturaleza, sea un libro sellado, un testimonio oculto, un enigma que no se puede resolver a

8 Hamann, J.G., Recuerdos socráticos y Aesthetica in nuce, op.cit, p.106.

9 La violencia de los acontecimientos históricos durante el siglo XX desvelará la vinculación entre el nihilismo y la política. Pöggeler, por ejemplo, afirmaría que los abismos a los que había llegado la política en el siglo pasado -incluso ya en el siglo XIX, como señaló Hannah Arendt-no habían sido otros que los abiertos por el nihilismo. Véase, Canterla, C.: «La cuestión del nihilismo en J.G. Hamann», op. cit., p.598.

10 Canterla, C., «La filosofía que ríe: la anatomía de la melancolía de Robert Burton y la metacrítica de la Ilustración», Daimon. Revista internacional de Filosofía, Suplemento 5 (2016), pp.807-816, p.814.

11 Canterla, C., «La cuestión del nihilismo en J.G. Hamann», op. cit., p.587. 
menos que aremos con otro buey que no sea nuestra razón». ${ }^{12}$ Ese otro buey es para Hamann una racionalidad no escindida de los sentimientos y pasiones, ni colocada por encima del cuerpo. Esta concepción, en clara sintonía con las ideas de Hume, se ha denominado racionalidad existencial.

Las pretensiones de este filósofo alemán iban dirigidas más bien a buscar una filosofía auténtica, una nueva metafísica que integrase de modo unitario a la naturaleza, el hombre y la historia, salvando todas las escisiones (cuerpo/mente, sensibilidad/entendimiento, ciencias naturales/ciencias humanas, poder/pueblo, naturaleza/cultura, mujer/hombre/, conocimiento/tradición, pensamiento/ lenguaje, etc.). En este sentido, estaba buscando también por esta vía, la de la insatisfacción respecto al liberalismo, una nueva forma de entender la racionalidad; por lo que es inexacta la interpretación de la obra de Hamann como un mero producto reaccionario de un irracionalismo místico-religioso. ${ }^{13}$

La ruptura de Hamann con la presunción de armonía y con el optimismo del que hacía gala la Ilustración significó un duro golpe para las aspiraciones universalistas de la Ilustración. Sin embargo, esto era de gran valor para los románticos, había definitivamente que admitir la derrota y asumir el carácter problemático y complejo de la vida. No obstante, la influencia de Hamann no terminó en el romanticismo, sino que sus ideas han influido de manera fundamental en autores como Soren Kierkegaard, Walter Benjamin, Ernst Jünger o Ludwig Wittgenstein. ${ }^{14}$

\section{GÜNTHER ANDERS Y EL TIEMPO DEL FIN}

A Günther Anders, que nació en 1902, lo separan casi dos siglos de Hamann. Como alumno de Husserl y Heidegger, entre otros, es fácil entender su interés inicial por el lugar que ocupa el ser humano en el mundo. Sus primeros escritos van encaminados a desarrollar una antropología filosófica que abordaba temas clásicos como la libertad. En un enfrentamiento filosófico y también personal con Heidegger (que convierte a Anders en uno de los primeros y más lúcidos críticos del filósofo de la selva negra), empieza a cuestionar el concepto de «ser-en-el-mundo». Durante la década de los años 30, los escritos de Anders ponen de manifiesto la ausencia de adecuación entre el mundo y los seres humanos.

12 Hamann, J.G., Recuerdos socráticos y Aesthetica in nuce, op. cit., p.58.

13 Canterla, C., Mala noche. El cuerpo, la política y la irracionalidad en el siglo XVIII, Fundación Lara, Sevilla, 2009, p.251.

14 Por ejemplo, Lauri Snellman ha publicado recientemente un artículo (incluido en la bibliografía) en el que se habla de la influencia de Hamann en la concepción del lenguaje de Wittgenstein. Una de las tesis clave que baraja la autora es que Wittgenstein adopta su teoría sobre el lenguaje en el mismo segmento de tiempo en el que lee y discute en sus diarios con Hamann. 
Sin embargo, los acontecimientos del momento truncarían, por un lado, sus ambiciones académicas y, por otro, le revelarían la futilidad de tales cuestiones filosófico-antropológicas. Los días 6 y 9 de agosto de 1945, los bombardeos sobre Hiroshima y Nagasaki acabaron con la vida de casi un cuarto de millón de personas. Estos acontecimientos supusieron una cesura en la vida y el pensamiento de Anders y le impidieron dar cuenta de lo que suponían estos hechos. Pasaron varios años hasta que pudo poner por escrito lo que significaba el desarrollo de la energía nuclear. La era atómica y el peligro irreversible de un exterminio a escala global se convirtieron entonces en sus preocupaciones no solo como intelectual sino también como activista. Porque para Anders, desde esa fecha, el verdadero problema al que nos enfrentamos no es que seamos seres sin mundo, ${ }^{15}$ sino la posibilidad de que «haya» un mundo sin seres humanos (o, tal vez, ni siquiera eso). Con el lanzamiento de la bomba atómica en Hiroshima la humanidad entra en una nueva era histórica, aquella en la que por primera vez -y ya para siempre- los seres humanos tenemos la capacidad de aniquilarnos y desaparecer como especie.

La pregunta que nos hacemos, siguiendo a Anders, sería cómo el proyecto ilustrado ha devenido en la bomba. Para él es consecuencia del desarrollo tecnológico, que da lugar a una división de tareas donde no se tiene a la vista un telos final. Cada uno, obstinado en su trabajo - que sólo es un paso- no percibe nada flagrante, nada inmoral, en lo que hace pues no percibe el producto final. Los campos de concentración, y Auschwitz en particular, son casos que Anders equipara a la bomba atómica. Adolf Eichmann, ejemplo paradigmático, defendió hasta el final su papel de mero engranaje; Hannah Arendt lo llamó «la banalidad del mal». Se nos ha concedido un poder ilimitado a nosotros, que somos seres finitos y con imaginación moral limitada. Estamos, dirá Anders, «ciegos ante el apocalipsis». ${ }^{16}$

La bomba supone la posible aniquilación de la humanidad en su conjunto. Pero Anders advierte que esto no debe ser tomado en el sentido heideggeriano de Sein-zum-Tode, como una extrapolación del ser solitario Dasein en su confrontación con la muerte como lo más propio (eingentlich), porque así se convertiría la catástrofe en algo positivo, es decir, «en la posibilidad de que

15 Anders, G., Mensch ohne Welt: Schriften zur Kunst und Literatur. C.H. Beck, München, 1984, p. XI. En esta obra se recopilan algunos trabajos sobre arte y literatura en los que Anders reflexiona acerca de la pérdida de mundo. Estos son una deriva de sus primeros trabajos encuadrados dentro de una antropología filosófica que pretendía caracterizar la situación del ser humano en el mundo y cómo se define en él. Más tarde, a partir de los años cincuenta, sus reflexiones y su activismo irán encaminadas a alertar sobre la posibilidad de que el mundo ya no siga existiendo.

16 Anders, G., Die Antiquiertheit des Menschen, Bd. 1: Über die Seele im Zeitalter der zweiten industriellen Revolution. C.H. Beck, München, 1956, p. 263. 
la humanidad 'llegue a ser auténticamente'». ${ }^{17}$ No es esta, únicamente, una cuestión geográfica sino también temporal, porque acabar con la humanidad significa que ya no la habrá más, ni tampoco existirá la que ya fue. La existencia no sería entonces un instante entre dos eternidades sino «entre dos nadas: aquella nada que ya nadie recordará que hubiera sido, como si nunca hubiese existido, y la nada que nunca será»». ${ }^{18}$ La bomba no sólo impide que algo pueda llegar a ser -esto es, impedir el futuro-, sino que aniquila todo lo que alguna vez ha sido: el pasado, la historia.

Anders entiende que hay dos raíces que explican esta «ceguera» ante el apocalipsis: una de carácter filosófico-antropológica y otra histórica. La primera se manifiesta en el «desnivel prometeico». Esta acuñación andersiana sintetiza la diferencia entre nuestras capacidades de producción (Herstellung) y de representación (Vorstellung). No es casual, afirma Anders, que no haya existido una «historia de los sentimientos». ${ }^{19}$ Efectivamente, tenemos conocimiento de una historia del pensamiento o de las ideas; también, una historia de la tecnología o de los descubrimientos científicos. Siendo así que los sentimientos han permanecido inalterados con el paso del tiempo. Entre los que se asocian a la imaginación y a la representación encontramos, por ejemplo, el sentimiento de responsabilidad moral. Mientras nuestra capacidad tecnológica para fabricar armas se ha desarrollado históricamente hasta niveles destructivos insospechados, nuestra capacidad para representarnos sus consecuencias $y$, por ende, de responsabilizarnos moralmente, ha permanecido inalterada desde la época de la lanza y la onda. En este sentido, sigue resultándonos más espeluznante la violencia ejercida sobre uno o varios (por ejemplo, las imágenes del terrorismo), que otro tipo de violencia causante de un número de víctimas mucho mayor.

La segunda raíz de la ceguera ante el apocalipsis es, para Anders, de carácter histórico: la fe en el progreso (der Fortschrittsglaube), es decir, la creencia en que todo lo que vendrá será siempre mejor que lo anterior. Se destierran así los conceptos «bueno»y «malo» en sentido absoluto. Lo «malo», ya convertido en grado, pasa exclusivamente a formar parte de lo pasado. Y lo «bueno» ya no existe ni siquiera como ideología de la redención, de la vida eterna cristiana como un punto «final» de consumación, pues siempre se dará la posibilidad de algo mejor. Pero tampoco los hechos catastróficos del siglo $\mathrm{XX}$, que llevaron a algunos a dudar de la fe ciega en el progreso, dieron lugar

17 Ibid., p. 245 y nota de la p. 243 (p. 345).

18 Anders, G., Hiroshima ist überall. C.H. Beck, München, 1982, p. 218.

19 Anders, G., Die Antiquiertheit des Menschen, Bd. 1: Über die Seele im Zeitalter der zweiten industriellen Revolution. C.H. Beck, München, 1956, p. 271. 
a un imaginario de un «mal final», sino que la ausencia de futuro se convirtió en un «presente como nunc stans del infierno» y así «también los nihilistas están ciegos para el apocalipsis». ${ }^{20}$

Una de las razones que lleva a Anders a afirmar que vivimos sin futuro, o en una eterna prórroga temporal, es el carácter de mediación que caracteriza el hacer humano en las sociedades tecnológicas modernas. Die Medialität, es decir, la división y especialización en los procesos productivos dificultan tener a nuestro alcance moral la finalidad de aquello que llevamos a cabo. Ya no somos actuantes, sino meros colaboradores. El producto final $-\mathrm{O}$ un posible uso- de un largo e intrincado proceso de fabricación, del que somos partícipes como engranajes, resulta desconocido al trabajador. Es propio de este trabajador (formulado en analogía con el problema fundamental del marxismo) «no ser nunca 'propietario' del conocimiento de las finalidades de la producción, por las que no tiene ningún interés». ${ }^{21}$

Anders afirmaba que el trabajo no huele. ${ }^{22}$ Esta es una referencia a la locución latina Pecunia non olet, ${ }^{23}$ que da a entender que el valor del dinero es independiente de su procedencia. En este caso, utiliza la referencia para enfatizar que el trabajo se tiene por valioso en sí mismo, sin tener en cuenta a qué fines sirve o qué se produce con él. Mientras impera una conciencia del trabajar como algo «moral», la finalidad y el resultado de ese trabajo «son considerados como 'moralmente neutrales'; da igual en qué se trabaje, el producto del trabajo está 'más allá del bien y del mal'». ${ }^{24}$ Esta es una deriva nihilista del trabajo en las sociedades tecnificadas. Anders atribuye esta característica tanto a los países capitalistas como a los del socialismo real y afirma que «si la mayor parte del hacer humano -y el trabajar constituye la mayor parte- está de antemano fuera del juicio moral, eso desemboca en el imperio efectivo del nihilismo». ${ }^{25}$

Los crímenes y los horrores del siglo XX, ya sean Hiroshima y Nagasaki o Auschwitz, no podían haberse dado en otra época, porque su carácter «está ligado estrechamente a la esencia de la época actual», es decir, un nihilismo

20 Ibid., p. 279.

21 Ibid., p. 288-289.

22 Ibid., p. 289.

23 Durante el mandato del emperador Vespasiano en la antigua Roma, se estableció un impuesto a la recogida de orina de las letrinas públicas, apreciada por los curtidores de pieles y por lavanderos dado su alto contenido en amoniaco. Según el historiador Suetonio, el hijo de Vespasiano mostró su descontento ante tales ganancias repulsivas, a lo que su padre respondió mostrándole e incitándole a oler una moneda de oro.

24 Ibid.

25 Ibid., p. 349-350 (nota de la p. 289). 
que para Anders se fundamenta en la «medialidad» del proceso productivo, convirtiendo al trabajador en mero engranaje y despojando de todo valor moral a lo producido.

Al mismo tiempo que los productos están «más allá del bien y del mal» podemos constatar que vivimos en una época en la que nos servimos de las cosas que producimos mucho más que en épocas anteriores. La mayoría de las acciones que llevamos a cabo, tanto en nuestra vida privada como profesional (una distinción que cada vez se desdibuja un poco más), están mediadas y son imposibles de realizar sin la intervención de las máquinas, los aparatos, y las herramientas que hemos fabricado. Se produce así un vuelco respecto a la manera en que consideramos la moralidad de nuestros quehaceres, que ya no depende directamente de nosotros, sino de las cosas como «medios». Esto, consecuencia directa del desnivel prometeico, nos conduce a la sensación de no sentirnos responsables. Las máximas que servían como reguladores morales dirá Anders que «se han convertido en cosas y modos de acción materializados». ${ }^{26}$

Ya no somos sujetos morales en el sentido clásico, sino que más bien «cada uno tiene aquellos principios que tienen los objetos que poseemos». ${ }^{27}$ Ya no es inmoral una acción, sino fabricar o incluso poseer un producto, aunque no se llegue a utilizar. Por lo tanto, quienes son poseedores de la bomba atómica o de hidrógeno, carecen de moral. Anders los sentencia así: «los dueños de la bomba son nihilistas en acción» porque «mientras el autor no destruya el aparato; mientras amenace con él, simplemente teniéndolo; mientras prosiga sus acciones, que sin razón denomina 'ensayos', tiene que ser considerado culpable. Y como el efecto de su actuar consiste en la aniquilación, también culpable de nihilismo; de nihilismo a escala global». ${ }^{28}$

La consecuencia de este nihilismo es la última de las consecuencias. La que caracteriza el tiempo del fin y marca el final del tiempo. Tras la aniquilación no se borra el futuro, sino también el pasado. Si la superación del nihilismo todavía fuera posible, tendría que sustentarse sobre una máxima como la siguiente: «Ten únicamente las cosas cuyas máximas de acción puedan convertirse también en máximas de tu propia acción». ${ }^{29}$ No puede ser considerado moral poseer una «cosa» cuyo único fin es el propio Fin(al). $\mathrm{Y}$, por ende, quienes poseen tal cosa como la bomba tienen la máxima que es propia de la bomba misma: su máxima es el «nihilismo».

26 Ibid., p. 298.

27 Ibid., p. 296.

28 Ibid., pp. 295-296.

29 Ibid., p. 298. 


\section{CONLUSIONES}

Abordando el pensamiento de Hamann y de Anders pretendemos poner en conexión dos momentos elementales en torno al debate del nihilismo: su origen y su consumación. Con esta vinculación, además, queremos reivindicar que, desde sus posiciones ex-céntricas ofrecen nuevas perspectivas y merecen estar en el centro del debate sobre el nihilismo que Jünger y Heidegger mantuvieron en el siglo XX. De esto se desprenderá la necesidad de actualizar el debate hasta el momento presente y sus implicaciones.

Los primeros puntos de conexión entre Hamann y Anders guardan relación con tres experiencias vitales. La primera vinculación está marcada por acontecimientos biográficos llamativamente similares. En ambos autores encontramos un punto de inflexión en su pensamiento: en Hamann tras la crisis en 1757 en Londres y, para Anders, el momento de cesura se produce en agosto de 1945 con el lanzamiento de Little Boy sobre Hiroshima.

Las ideas de Hamann y Anders se anticipan a las de su época, lo que nos conduce al segundo punto de esta conexión: la incomprensión y la desatención de su pensamiento por parte de sus contemporáneos. La crítica de Hamann no obtuvo un reconocimiento a la altura de lo que planteaba; no sólo porque criticaba el movimiento ilustrado en pleno desarrollo del mismo, sino por la poca ortodoxia con la cual criticó al concepto mismo de razón. ${ }^{30}$ Su incomprensión se corresponde con la de Anders, considerado un outsider en el siglo XX, catalogó su propia obra como una Gelegenheitsphilosophie, es decir, una «filosofía de la ocasión» que definió como un cruce entre periodismo y metafísica.

El tercer punto de conexión vital se centra en el antiacademicismo de los dos autores. Por ejemplo, Hamann se burla en sus Recuerdos socráticos de las grandes obras de los intelectuales de su época, grandes más por el tamaño que por su contenido, ya que, según él, simplemente eran palabrería fruto del orgullo del autor. Por su parte, el giro que llevó a Anders a convertirse en un «filósofo moral» estuvo caracterizado por una crítica a sus colegas universitarios. El problema central que ahora ocupaba sus reflexiones no era ya una cuestión de especialistas, sino de toda la humanidad y criticó, entre otros, a Adorno por «hacer panes sólo para otros panaderos». Las vivencias que hemos señalado marcaron fuertemente la manera de hacer filosofía de los dos autores. No es posible dar sentido a sus reflexiones sin tenerlas en cuenta.

La problemática de la contraposición entre lo aparente y lo real es tratada

30 Para ahondar más sobre la desvinculación de Hamann del irracionalismo del que se le acusó durante varios siglos y conocer las nuevas lecturas que se están haciendo de su pensamiento véase: Hernández Pérez, A., «Johann Georg Hamann: un foco de resistencia en épocas de absolutismo de la razón ilustrada», en Logos. Anales del Seminario de Metafísica 51, (2018), 219-237. 
por ambos autores como síntoma o manifestación del nihilismo. Tanto uno como otro se percataron de que el verdadero peligro está en lo que es velado. Ya sea un sistema filosófico vacío o una central nuclear. El recurso del Sileno es utilizado por Hamann como figura para la crítica. Entendía que lo que aparentemente se mostraba como excelso, brillante y solemne, en los contornos del panorama intelectual, no era más que la máscara de un «vacío» o del horror. Por un lado, criticaba el aura supuestamente virtuosa de los intelectuales $\mathrm{y}$, por otro lado, denunciaba el contenido «nihilista» de sus magnas obras. En ese sentido comenta: « ¡Ved! La grande y pequeña masora de la filosofía ha inundado, como un diluvio, el texto de la naturaleza». ${ }^{31}$ «Masora» hace referencia a una trasmisión de la tradición hebrea encargada de prefijar el sentido de un texto religioso a través de claves. Hamann utiliza esta metáfora para dar a entender que las construcciones filosóficas de la Ilustración impiden la posibilidad de interpretar de manera diferente la naturaleza.

La exaltación de la apariencia o el poder de la imagen en el siglo XX es una cuestión referencial en el pensamiento de Anders y aparece como continuación de las reflexiones tratadas por la Escuela de Frankfurt. En lo que nos ocupa, el poder destructivo de la bomba aparece velado por su imagen de «mero» armamento. Y quienes poseen la bomba se convierten en silenos invertidos, como se señaló más arriba, porque sus valores son aquellos del objeto. Una vez desplazado del foco de interés, nos queda la manifestación de la energía atómica en las centrales nucleares, cuya imagen no desvela absolutamente nada de su poder destructivo.

Dicho poder destructivo sería, para Hamann, consecuencia directa de la insensibilidad generada por la melancolía de la razón, la cual la hemos definido como una patología; obsesionada por la desafección absoluta de la corporeidad y sus elementos. Este pensar a sangre fría en conjunto con todas aquellas construcciones culturales violenta al individuo y deja una profunda huella en la moral. Huella que también constató el propio Anders. Hoy empieza a ser reconocido su concepto de «desnivel prometeico», mencionado más arriba. Con la escisión radical entre la razón (ese pensar a sangre fría) y el sentir (dependiente del poder de imaginar) se vuelve imposible responsabilizarnos de las consecuencias de todo aquello que producimos. Siendo así que la tarea más apremiante de nuestro tiempo sería, de acuerdo con Anders, «la educación de la fantasía moral».

El propio d'Alembert ${ }^{32}$ contemporáneo de Hamann, describe con enorme satisfacción cómo su siglo experimenta un cambio donde -gracias a la efervescencia intelectual-sólo el tiempo dirá hacia dónde habrá de llevarnos

31 Hamann, J.G., Recuerdos socráticos y Aesthetica in nuce, op. cit., p.103.

32 D“Alembert, Discurso preliminar de la Enciclopedia, Aguilar, Buenos Aires, 2010. 
esa fe ciega en la razón y el progreso, es decir, hasta donde llegaría el nihilismo. Hubo de entrar en la escena histórica el siglo XX con toda su brutalidad, para apaciguar ese entusiasmo. O, al menos, para dudar del progreso. Para Anders, el inicio de la era atómica es un punto de no retorno. No hay posibilidad de rebasamiento, como en Jünger, porque el agotamiento del nihilismo significa su consumación.

Los peligros velados de la energía nuclear, tal como los describía Anders, amenazan con la materialización de un «globocidio» en potencia. Sin embargo, nuevas amenazas emergen con apariencias todavía más inocuas. En esta segunda Ilustración, en palabras de Byung-Chul Han, ${ }^{33}$ hemos de estar alerta ante nuevas formas veladas de violencia. El mito del Big data y su pureza (los datos no mienten) revela una nueva forma de nihilismo. Los datos, en sí mismos, carecen de sentido. La máscara que los cubre y sobre la que se elabora una narración para dotarlos de sentido, no atiende a su significación intrínseca -porque los datos carecen de ella- sino, más bien, a los intereses velados de las grandes corporaciones y de los gobiernos. Esta nueva era obsesionada con medir hasta el último rasgo vital construye castillos de naipes sobre el vacío de los datos, perpetuando algunos de los rasgos nihilistas denunciados por Hamann y Anders.

Desde hace algún tiempo teóricos de la tecnología como Paul Virilio o Robert Hassan han concebido la velocidad como un rasgo plenamente Nihilista. Virilio a través de su concepto de dromologia muestra la naturaleza de la velocidad, las condiciones de su aparición, sus transformaciones y efectos, y cómo dicho culto representa la propaganda del progreso. Este nuevo espacio, que denomina espacio-velocidad, tiene, según él, consecuencias devastadoras. Por ejemplo, la forma no física en este tiempo incrementa de alguna manera el miedo de las personas, que tienen la impresión de que la tierra se contrae y se reduce el espacio; comprimido por un tiempo instantáneo. Esta huida hacia adelante que representa la aceleración puede llevarnos a administrar dicho miedo en lugar de superarlo. Dicha administración acaba por significar la «liquidación del mundo». Este tipo de pesimismo cultural es compartido por Robert Hassan, el cual considera que este tiempo de red cada vez más comprimido, la velocidad pura, coloniza todos los aspectos de la vida, sin dejar tiempo para la lectura, la reflexión y la resistencia. Esta búsqueda incesante de la velocidad se convierte en una patología, una adicción inevitable que nos lleva a correr cada vez más deprisa sin movernos del sitio. En ese sentido, aunque desde una posición menos pesimista, Judy Wajcman, entiende que

33 Han, B-C., Psicopolitica, Herder, Barcelona, 2014. 
estos autores aciertan en el diagnóstico de algunos grandes peligros que están emergiendo por el avance de la tecnociencia, incluso, comparte la visión crítica sobre el rasgo nihilista que acompaña a la velocidad. ${ }^{34}$

Más allá de las similitudes que vinculan a estos dos autores, podemos concluir que algo esencial los diferencia: Hamann no tenía motivos de peso para ser pesimista y que los sucesos de Hiroshima y Nagasaki impidieron que Anders pudiera mirar al futuro con algún atisbo de optimismo. El nihilismo fue para ellos -y aún lo es hoy para nosotros- real. Para que la humanidad no alcance un límite no retornable, esto es, su final, debemos recuperar el carácter crítico de estos dos pensadores a menudo denostados y, sobre todo, olvidados no sólo por el público en general sino también por el académico. En definitiva, la actitud crítica de estos dos filósofos nos permite afrontar un futuro que será siempre incierto, y hacerlo con los ojos abiertos ante los velados peligros del poder de una razón abstracta, mecánica e instrumental que sigue campando a sus anchas.

\section{REFERENCIAS BIBLIOGRÁFICAS}

ANDERS, G., Die Antiquiertheit des Menschen, Bd. 1: Über die Seele im Zeitalter der zweiten industriellen Revolution, C.H. Beck, München, 1956.

ANDERS, G., Hiroshima ist überall, C.H. Beck, München, 1982.

ANDERS, G., Mensch ohne Welt: Schriften zur Kunst und Literatur, C.H. Beck, München, 1984.

BETZ, J.R., After Enlightenment: the post-secular vision of J. G. Hamann, WileyBlackwell, Oxford, 2009.

CANTERLA, C., «La cuestión del nihilismo en J.G. Hamann», Pensamiento, 70 (2014), núm. 264, pp. 577-600.

CANTERLA, C., «La filosofía que ríe: la anatomía de la melancolía de Robert Burton y la metacrítica de la Ilustración», Daimon. Revista Internacional de Filosofía, Suplemento 5 (2016), pp.807-816.

CANTERLA, C., «La metacrítica de la razón ilustrada en Hamann», Daimon. Revista Internacional de Filosofia, suplemento 2, 2008, pp.337-345.

CANTERLA, C., Mala noche. El cuerpo, la política y la irracionalidad en el siglo XVIII, Fundación Lara, Sevilla, 2009.

CASSIRER, E., Filosofía de la ilustración, Fondo de cultura económica, México, 2008.

HAMANN, J.G., «La metacrítica sobre el purismo de la razón pura», en: ¿Qué es Ilustración?, Tecnos, Madrid, 2007.

HAMANN, J.G., Recuerdos socráticos y Aesthetica in nuce, Hermida Editores, Madrid, 2018.

HAN, B-C., Psicopolítica, Herder, Barcelona, 2014.

34 Wajcman, J., Esclavos del tiempo, Paidós, Barcelona, 2017. 
HASSAN, R., Empires of Speed. Time and the Acceletarion of Politics and Society, Brill Academic Publisher, Leiden, 2009.

HERNÁNDEZ PÉREZ, A. «Johann Georg Hamann: un foco de resistencia en épocas de absolutismo de la razón ilustrada», en Logos. Anales del Seminario de Metafísica 51, (2018), 219-237.

SEOANE, J., La Ilustración heterodoxa: Sade, Mandeville, Hamann, Espiral Hispano Americana, Madrid, 1998.

SNELLMAN, L., «Hamann's Influence on Wittgenstein», Nordic Wittgenstein Review 7 (1) 2018 pp. 59-82.

VIRILIO, P., Speed and Politics, Semiotext[e], New York, 1986.

WAJCMAN, J., Esclavos del tiempo, Paidós, Barcelona, 2017.

Abraham Hernández PÉrez es personal docente investigador de la Universidad de la Laguna.

Líneas de Investigación:

Filosofía de la ciencia

Publicaciones recientes:

(2018). «Johann Georg Hamann: un foco de resistencia en épocas de absolutismo de

la razón ilustrada» Logos. Anales del Seminario de Metafísica 51, 219-237

2020. «Sandra Mitchell», en M. Vázquez e I. Perdomo (eds.), El mes de las filósofas.

La Laguna: Filosofía ULL, BLURB.

Correo electrónico: abhp.philosophy@gmail.com

RAYCo Herrera es profesor Doctor en Filosofía.

Lineas de Investigación:

Filosofía de la Tecnología

Publicaciones recientes:

(2020). «La continuación de la antropología filosófica de Günther Anders en el mundo tecnificado» (en prensa).

(2019). «Trabajo y Automatización. Una mirada al futuro del empleo con Günther Anders», en Ensayos desde la perplejidad. Homenaje a Javier Muguerza. La Laguna: Universidad de La Laguna.

Correo electrónico: rayco@outlook.com 